\title{
Erro e ruído na tecnocultura contemporânea
}

\author{
Entrevista com Peter Krapp, efetuada por \\ Eduardo Harry Luersen' \\ Guilherme Malo Maschke' \\ I - Unisinos \\ São Leopoldo (RS), Brasil
}

Resumo: Entrevista realizada com o professor Peter Krapp (Universidade da Califórnia), durante sua participação na XVI Semana da Imagem, evento realizado junto ao PPG em Ciências da Comunicação, da Universidade do Vale do Rio dos Sinos. Nesta entrevista são abordados temas relacionados à obra mais recente do autor, Noise Channels (2011), como a estetização do erro na cultura digital, os princípios ergonômicos presentes no desenvolvimento das interfaces gráficas de usuário e a relação entre ruído e tecnocultura na produção musical contemporânea.

Palavras-chave: tecnocultura; ergonomia; mídias digitais; ruído.

Abstract: Glitch and error in contemporary digital culture. Interview with Peter Krapp - Interview with Professor Peter Krapp (University of California), due to his participation in the 16th Semana da Imagem, an event held at Universidade do Vale dos Rio dos Sinos. In this interview, we approach the author's most recent work, Noise Channels (2011), to discuss themes such as the aestheticization of error in digital culture, the ergonomic principles which play a central role in the development of graphical user interfaces and the relation between noise and digital culture in contemporary music production.

Keywords: technoculture; ergonomics; digital media; noise.

A presente entrevista se fez possível quando da participação do professor Peter Krapp na XVI Semana da Imagem, evento promovido pelo grupo de pesquisa Audiovisualidades e Tecnocultura: Comunicação, Memória e Design - TCAv ${ }^{1}$, vinculado ao PPG em Ciências da Comunicação da Unisinos. O evento é organizado anualmente pelo grupo, visando pensar o estatuto da imagem no contexto da tecnocultura contemporânea. A edição mais

1 Disponível em:<http://tecnoculturaaudiovisual.com.br>, acesso: 28 mar 2018 
recente propôs discussões concentradas sobre o tema Design, Imagem e Tecnocultura, que tem ocupado um papel central nas reflexões atuais do TCAv (2015).

Peter Krapp é professor no Departamento de Estudos de Cinema e Mídias da Universidade da Califórnia, em Irvine, e pesquisa a cultura audiovisual através de um olhar voltado à história das mídias, à memória cultural e às materialidades da comunicação. Ao longo de seu livro mais recente, Noise channels: glitch and error in digital culture (2011), Krapp mapeia uma diversidade de formas de glitches, bugs e lags que se propagam nas estéticas da cultura digital. No cerne de seu trabalho, o pesquisador reanima teorias da informação e do design para abordar o excedente criativo proporcionado pelo ruído nas mídias e processos correlatos que envolvem as formas atuais de interação humano-computador.

Enquanto alunos e membros do TCAv, vínhamos discutindo a sua obra em reuniões do grupo e disciplinas ofertadas pela Linha de Pesquisa Mídias e Processos Audiovisuais. Conduzimos esta entrevista com Krapp por e-mail, para debater com o próprio pesquisador sobre alguns dos temas centrais apresentados em seu livro.

PERGUNTA: Em seu livro Noise channels: glitch and error in digital culture, as interfaces humano-computador se tornam um lócus para observarmos as manifestações criativas da tecnocultura contemporânea. Diante do que você chama de "gerenciamento de possibilidades", que é ofertado pelos princípios ergonômicos presentes no design de interfaces das chamadas novas mídias, - frequentemente ligados à ideia de tornar o computador invisível para um usuário -, é razoável pensarmos nos erros e bugs como aberturas para possibilidades criativas na atual ecologia das mídias? Neste contexto, qual a importância e o papel do acaso, em sua ação de limiar entre projetos de interface redundantes que propõem ações hermeticamente delimitadas por regras e a indeterminação que se supõe alheia a tais projetos?

Peter Krapp: A ergonomia não tem uma história muito longa. A noção de interface é ainda mais recente. Depois que a revolução industrial introduziu novos desafios ao modo como os seres humanos trabalham, se locomovem, consomem informações e compartilham bens, o chamado desenvolvimento "fordista" pareceu para muitos observadores mais uma relação do tipo "humanos contra as máquinas" do que algo como "seres humanos com máquinas" - menos um ambiente colaborativo do que uma forma de confronto. De fato, as condições de trabalho mudaram e os riscos de acidentes aumentaram. Assim, consultores e gerentes (duas profissões que surgiram na época por essas mesmas razões) como Gilbreth ${ }^{2}$ criaram maneiras de proteger o corpo humano contra esforços repetitivos, e a prevenção de lesões tornou-se uma prioridade. Por volta da mesma época, integrar ou reintegrar pessoas feridas na Primeira Guerra Mundial ao local de trabalho se

2 Frank Bunker Gilbreth (1868-1924), engenheiro e consultor norte-americano. Célebre porta-voz do modelo de Administração Científica baseado em ideais de produtivismo e racionalização da força de trabalho. Gilbreth é mais conhecido por sua defesa de uma noção de administração eficiente a partir do controle dos movimentos realizados na rotina de trabalho. 
tornou um desafio sério. Como você treina alguém para ser um datilógrafo, um pedreiro, uma costureira, ou um operário de fábrica eficiente, e como você integra alguém que tem uma lesão na perna, um dedo faltando, ou uma dor nas costas? Perguntas como estas levaram à melhoria das condições de trabalho - mesas e assentos ergonômicos, além de ambientes de trabalho que reduziam a probabilidade de erros, acidentes e lesões, permitindo que as pessoas com ferimentos de guerra voltassem à atividade. Quando a computação entra no ambiente de trabalho, estas questões já estão postas, e a noção de interface (que não mudou tanto quanto se gostaria de pensar nas últimas oito ou mais décadas) nutre-se dos princípios básicos da ergonomia, para que as pessoas possam realizar tarefas repetitivas com o grau de eficiência que as poupa da fadiga e de lesões.

A interface gráfica, que esconde efetivamente o funcionamento das máquinas do usuário, e a miniaturização de dispositivos cujas funções frequentemente residem "na nuvem", e não no pequeno aparelho portátil que temos em nossas mãos, inviabilizaram um maior conhecimento sobre estas máquinas - incluindo o conhecimento que elas coletam sobre nós, como percebemos no caso das redes sociais...

Este conto tecnocrático de um século de gestão e consultoria, no entanto, aponta para a possibilidade de que erros e bugs originem programas criativos, assim como vocês colocaram. No meu livro, tento explorar alguns deles - machinima e outros vídeos de jogos, mas também a música, a net art, o midiativismo, e assim por diante. Porque, de modo muito sucinto, pode-se dizer que quanto mais a interface restringe o nosso acesso ao armazenamento, ao processamento e à transmissão de informação e de entretenimento, mais queremos voltar ao loop homem-máquina e explorar o seu funcionamento interno. E é nessa dialética entre ocultação conveniente de informações e conhecimento pleno que eu situo a discussão da contingência - e a reflexão teórica sobre a contingência há muito se associa ao potencial estético. Tento examinar até que ponto um jogo é um espaço para contingência - nem todo teórico da arte concordaria que o jogo é a melhor forma para elucidar esse problema, mas eu achei produtivo. O pensamento sistemático muitas vezes evita a contingência para enfatizar a determinação, a necessidade e as regras.

Porém, ao mesmo tempo em que os jogos possuem regras, eles também são projetados para atividades lúdicas que ocasionalmente desafiam as regras. Sem dúvida, a experiência estética é um refúgio tradicional do acaso, do acidente e do jogo diante da sua exclusão filosófica (e teológica), e isso ainda procede na era dos a ambientes a mediáticos hightech, altamente controlados e previsíveis.

PERGUNTA: Discutindo a importância de mobilizar projetos experimentais e nutrir posturas especulativas na abordagem às chamadas novas mídias, Benjamin Bratton (2016) afirma que uma das tarefas ético-políticas fundamentais do design do século XXI é desconstruir o design do século XX. Em seu livro, você discute alguns conceitos que com frequência definem as perspectivas projetuais das novas mídias, como ergonomia 
e imersão, para citar alguns, situando-os em um cenário histórico mais amplo do design de interfaces. Neste aspecto, gostaríamos que você comentasse sobre o papel do ruído (se é que ele tem um) em processos de desconstrução de noções como ergonomia e imersão. Ou se você considera, por outra via, que seria mais proveitoso pensar nas mídias contemporâneas como compartes em uma negociação perene e continuada com estéticas ruidosas, na produção de diferença nos artefatos midiáticos?

Peter Krapp: Trata-se de um conjunto de perguntas muito complexas - será que o ruído pode desconstruir a noção de ergonomia ou de imersão? Minha sensação é de que tomar exemplos da cultura digital pode não ser suficiente para verificarmos se este é o caso. Para encaminhar uma resposta satisfatória, é necessário percebermos a tensão implicada na sua descrição (como na de meu amigo Ben Bratton) da tarefa deste século como a de desfazer o legado do século passado. Para mim, qualquer tentativa de "desconstruir" precisa reconhecer que, ao inverter uma hierarquia, você pode não desfazer o poder o que os termos implicados na relação ainda mantêm sobre nós. É claro, a tarefa para uma estética das mídias do século XXI certamente envolve a superação de antigas metáforas de interface que herdamos de tempos atrás (a área de trabalho, a pasta, o arquivo, a lixeira etc.), bem como a busca pelo acesso intuitivo ao potencial máximo da computação em rede para a informação, entretenimento e arte em escala humana. Ao mesmo tempo, isto não é capaz de desfazer a mudança fundamental que ocorreu no século XX, quando a informação, o entretenimento, a arte, a vida social, o trabalho e a educação incorporaram a lógica da computação em rede. Contar com o potencial criativo e político das interações contingentes, acidentais e ruidosas em um ambiente cada vez mais controlado não é a mesma coisa que transformar a internet nos sonhos anárquicos de H.G. Wells (1999), quando escreveu sobre o cérebro do mundo, ou de Paul Otlet (1989), quando prenunciou aquilo que Vannevar Bush (2003) resumiu como as lições fundamentais para o trabalho colaborativo em rede, em seus textos seminais sobre gestão tecnológica e governança global.

As expressões criativas podem parecer ruidosas por não corresponderem ao uso convencional, domesticado e previsível da rede - ainda assim, qualquer lampejo inesperado de interação performativa é rapidamente apropriado, estetizado e reinserido no fluxo de dados. As intervenções teóricas e técnicas seminais que procuram regular a relação entre ruído e sinal se configuram de tal modo que a rede reduz a probabilidade de acidentes e erros; mas o que constatamos é que, necessariamente, todos os nossos canais são endemicamente ruidosos. Portanto, não proponho revalorizar o ruído como algo virtuoso ou perturbador, e nem procuro desvalorizar as propriedades e possibilidades do armazenamento, transmissão e processamento "limpo" de informações como sendo desumanamente mecânicos.

A questão fundamental é sempre a quem tal atividade serve. Então, quando vocês perguntam se seria mais útil pensar nas mídias digitais a partir de uma negociação com 
estéticas ruidosas, eu digo: sim, a estética deve reservar espaço significativo para o ruído, para a contingência e a imprevisibilidade - justamente porque se isso não acontecesse, ela não iria surpreender, nem informar, nem desviar, nem entreter, e talvez nem mesmo ser perceptível. É por isso que meu livro discute que devemos estar familiarizados tanto com a tecnologia e suas condições de possibilidade para a arte quanto com a estética e suas antigas (ou mais recentes) tentativas de analisar os códigos e os canais de nossas experiências.

PERGUNTA: No capítulo Noise floor: between tinnitus and raw data, você lista uma série de acontecimentos em torno da música que foram modificando as suas formas e até mesmo o significado estético do termo música. As experiências pós-tonais como dodecafonismo, atonalismo e serialismo integral seriam rupturas com um passado secular da música tonal. Acompanhando-as, ainda, há experimentos com tecnologias de reprodução e produção musical, como a música concreta e a música eletrônica. Posteriormente, o advento da música computacional com Max Mathews ${ }^{3}$ e demais derivações de sons gerados por computadores. A música hoje está permeada por essas técnicas e a linha entre música e ruídos parece estar cada vez mais apagada. Bandas atuais muito populares, como Death Grips ${ }^{4}$, utilizam diversos sons que poderiam ser considerados como ruído, e gêneros como a Noise music e o Power Electronics, voltados a uma estética agressiva e "anti-musical" (mais próximo de raw data, poderíamos dizer) se consolidaram como estilos. O desenvolvimento tecnocultural dessas técnicas gerou uma ampliação da concepção de música, e aquilo que antigamente era considerado como ruído está cada vez mais presente na linguagem musical. Comenta-se que o significado, o reconhecimento de um som, dá-se pela melodia, por uma semântica da duração, do ritmo e do timbre. Todavia, parece que hoje existe uma potência de produção de sons cada vez mais complexos, frutos de processamento intenso, e que acabam por impossibilitar um reconhecimento imediato com relação a um referente já ouvido. A música se expande para um espaço de sonoridades a-significantes, através de sons irreconhecíveis, muitas vezes com uma estrutura rítmica aberta e de difícil assimilação. Como esta impossibilidade significativa afeta a forma de lidar com a música, e até que ponto a tecnocultura está implicada nesse processo?

Peter Krapp: Vocês acertam ao apontar que os desenvolvimentos técnicos expandiram a noção do que consideramos aceitável na música e também nossas noções sobre o que as diferentes formas de música buscam realizar. Mas algo semelhante ocorreu mesmo antes da introdução da gravação, da computação, dos experimentos eletroacústicos etc.

Conforme recupero rapidamente no livro, o desenvolvimento técnico tem possibilitado transformações estéticas há séculos. Isto não significa dizer que um tecnodeterminismo

3 Max Mathews (1926 - 2011) foi um engenheiro elétrico pioneiro na música computacional. Conhecido por desenvolver a linguagem de programação MUSIC, que deu segmento a diversas ramificações, como os softwares Max/MSP e Pure Data.

4 Grupo de hip-hop experimental norte-americano, formando em 2010 e composto por MC Ride (Stefan Burnett), Zach Hill e Andy Morin. O grupo é conhecido por sua música agressiva com batidas quebradas, em uma mistura de punk, música eletrônica e música industrial. 
nos impele a reduzir a música àquilo que é viável em um dado momento, mas obviamente compositores e músicos têm abraçado há muito o desafio de incorporar os mais diferentes sons.

Vocês questionam a distinção entre som musical e ruído, e no livro eu trabalho com várias formações discursivas. Algumas delas são distinções formais ou estéticas; outras são abordagens estritamente racionais, como por exemplo a tentativa de instrumentalizar a teoria da informação para distinguir ruído e sinal. Em todo caso, é preciso admitir que o que há de interessante na música é que ela pode e deve permanecer livre para a exploração dos potenciais de surpresa, variação, acidente e improvisação, sobretudo na medida em que se torna gradativamente mais técnica - da habilidade do intérprete aos instrumentos musicais, e o da paleta sonora do compositor/arranjador às mais diversas formas de distribuição e de escuta.

Uma distinção tradicional entre som musical e ruído normalmente depende da separação entre intencional e não-intencional - o que se torna difícil de controlar ao tocarmos um instrumento de palheta como oboé, por exemplo, ou um instrumento forte como o violino. Mas ainda há potencial para sons não-intencionais mesmo quando os meios técnicos se tornam cada vez mais restritivos e circunscritos - pode haver feedback controlado ao tocarmos guitarra, mas ainda podem surgir ruídos e chiados não-intencionais do amplificador; pode haver cadeiras arrastando, pessoas tossindo na plateia, problemas com o microfone, falhas nas cordas vocais do cantor etc. Talvez algumas dessas imperfeições sejam, na verdade, parte integral da experiência estética de um belo concerto, enquanto que a remoção precisa destes sons em uma gravação limpa e "perfeita" pode deixar os mesmos ouvintes apáticos. E, de fato, às vezes o músico quer que você ouça as imperfeições de um arco, de uma voz, de um acorde, de um ritmo - isso mantém as coisas interessantes, e nos lembra da parte humana mesmo dentre as estruturas da tecnologia de ponta que por vezes cercam os artistas.

Uma distinção menos tradicionalista para tentar definir aquilo que é inesperado no evento estético diante de um horizonte de expectativas, pode ser formalizada em termos de probabilidade e de estatística. E isto é claro: embora uma abordagem baseada na teoria da informação nos permita compreender muito sobre a história das mídias digitais, talvez ela nunca possa dar a ver o apelo estético completo para nós, seres humanos, pois permanecemos como dispositivos ruidosos de banda estreita, com mais preferências irracionais e emocionais do que puramente intelectuais com relação ao consumo de música... Então, sim, mesmo quando testemunhamos a eficiência do progresso técnico em banir o imprevisível e o não-intencional de nossas formas de arte, ainda percebemos que músicos, intérpretes e compositores trazem de volta esses elementos incluídos-excluídos e exploram o seu potencial estético. O glitch, o click, o feedback etc, tornam-se elementos de um jogo sônico, e sua falta de significação é convertida em sinal. Esta inversão e reavaliação do ruído é interessante, pois demonstra que estamos sempre lidando com uma relação, com um coeficiente, e não com duas gamas distintas de sons. 
Nem todo ouvinte, e certamente nem todo músico, gostaria de exprimir sua atividade em termos tão abstratos quanto os da teoria da informação, ou de pensá-la do ponto de vista da história da mídia. Mas acredito que o meu capítulo mostra que existem alguns caminhos muito interessantes para trilhar nesta direção, caso alguém esteja disposto a fazer as conexões entre a comunicação estética e as suas condições técnicas de possibilidade.

\section{Nota sobre Peter Krapp}

Peter Krapp é professor da Universidade da Califórnia, em Irvine, nos departamentos de Informática, de Inglês e de Música, e professor e coordenador do departamento de Cinema e Mídias (Film \& Media Studies), na mesma Universidade. Antes de Irvine, lecionou na Universidade de Minnesota e na Bard College. Também foi professor visitante em programas de graduação e pós-graduação na África do Sul, na Alemanha, em Taiwan e nos Estados Unidos. Suas palestras e seminários abrangem uma diversidade de temas, tais como as políticas do arquivamento, sigilo e privacidade, jogos de computador, cultura digital, design tipográfico, teoria das mídias e arte-mídia.

Co-editou e organizou as coletâneas Medium Cool, em 2002, e Handbook LanguageCulture-Communication, em 2016, e é autor de dois livros: Déjà Vu: Aberrations of Cultural Memory (2004) e Noise Channels: Glitch and Error in Digital Culture (2011). No primeiro realiza uma aproximação entre a memória cultural e os temas da lembrança e do esquecimento. Transitando entre media studies, literatura comparada e a filosofia da história, Krapp evoca a noção de déjà vu como uma interface para pensar sobre os processos midiáticos e a rememoração sob uma perspectiva crítica e, por conseguinte, abordar as imbricações éticas, estéticas e políticas em jogo nas expressões individuais e coletivas da memória nas mídias contemporâneas; no segundo, Noise Channels: Glitch and Error in Digital Culture (2011), aproxima-se do fenômeno do glitch e sua manifestação nas mais variadas expressões da cultura digital, desde os jogos de computador, passando pela música eletrônica, até o design de produto. Neste trajeto, recupera alguns conceitos da teoria da informação e da cibernética para reavaliar a noção de ruído à luz da tecnologia das mídias digitais, o que o permite transitar entre a endemia do ruído nos canais de comunicação e o excedente criativo nas manifestações culturais contemporâneas.

Traduzido do inglês por Eduardo Harry Luersen. Nota elaborada por Eduardo Harry Luersen e Guilherme Malo Maschke 


\section{Referências}

BRATTON, B. On speculative design. In: Dis Magazine. The time complex: postcontemporary issue, 2016. Disponível em: http://dismagazine.com/discussion/81971/on-speculative-design-benjamin-hbratton/. Acesso em 13 dez. 2017.

BUSH, V. As we may think. In: MONTFORT, Nick; WARDRIP-FUIN, Noah. (org.) The new media reader. London: MIT Press. 2003.

KILPP S. (Org.). Tecnocultura audiovisual: temas, metodologias e questões de pesquisa. Porto Alegre: Sulina, 2015.

KRAPP, P. Noise channels: glitch and error in digital culture. Minneapolis: University of. Minnesota Press, 2011.

OTLET, P. Traité de documentation: le livre sur le livre, théorie et pratique. Liège: Éditions du Centre de lecture publique de la Communauté française de Belgique, 1989.

WELLS, H. G. World brain. North Stratford: Ayer Company Publishers, 1999.

Texto recebido em 26/04/2018

e aprovado em 08/08/2018. 